\title{
Bacterial Profile and pattern of antimicrobial drug resistance in Diabetic foot ulcers at Tertiary care hospital
}

\author{
Chavan S K ${ }^{1}$, Karande GS ${ }^{2}$, Chavan K B ${ }^{3}$ \\ ${ }^{1}$ Dr S K Chavan, Associate professor, ${ }^{2}$ Dr G S Karande, Professor and Head, Department of Microbiology, Krishna \\ Institute of Medical Sciences Karad.$^{3}$ Dr K B Chavan, Paediatrician, Karad, Maharashtra, India.
}

Corresponding Author: Dr S K Chavan, Email: surekhak12312@rediffmail.com

\begin{abstract}
Background: Worldwide diabetic foot is a major medical problem leading to disability and economic instability to family and country. Objectives: To assess the clinical and bacteriological profile of diabetic foot ulcer among rural Indian residents. Also to know the prevalent pattern of antimicrobial resistance of most commonly isolated organisms to various currently in use antimicrobial agents. Methodology: From 78 cases of diabetic foot ulcer, identification of isolates was done using standard microbiological techniques. Antibiotic sensitivity testing were carried out followed by detection of ESBL, MRSA, AmpC and MBL producing strains as per the CLSI guidelines. Results: In our study, a total of 78 specimens were cultured and $97.4 \%$ ulcer showed growth of organisms (76/78). Of the total 139 isolates, 134 (96.4\%) were aerobes and only $5(3.6 \%)$ isolates were anaerobes. An average of 1.8 organisms per lesion was isolated. Among the aerobes, 93 (69.4\%) gram negative and 41 (30.6\%) gram positive organisms were isolated. Pseudomonas aeruginosa $23.9 \%$ was predominant organism followed by Klebsiella species $(20.9 \%)$. A total $41(30.6 \%)$ aerobic gram positive bacteria were isolated. Staphylococcus aureus was the most common gram positive organism $28.4 \%$ in which Methicillin resistant S. aureus (MRSA) was 57.9\%. Among gram negative organisms 46(49.5\%) isolates showed ESBL production. Among ESBL producing strains Escherichia coli $68.3 \%$ isolates recorded highest ESBL activity followed by Pseudomonas aeruginosa $62.5 \%$ and Klebsiella species $53.6 \%$. Conclusion: The present study has shown that diabetic foot infections are polymicrobial in nature and commonly caused by multi drug resistant gram negative organisms.
\end{abstract}

Keyword: Bacterial isolates, Diabetic Foot Ulcer, Extended Spectrum Beta- Lactamase, Methicillin resistant S. aureus.

\section{Introduction}

Diabetes Mellitus is a chronic disorder affecting a large segment of population and in present scenario it act as major public health problem in India [1]. Among diabetes related complications, foot ulceration is the most common, affecting approximately $15 \%$ of diabetic patients during their lifetime [2]. Limb amputation has major impact on the individual, not only distorting body image, but also with regard to loss of productivity, increasing dependency, and cost of treatment [3].

Selecting appropriate antimicrobial therapy for diabetic foot infections requires knowledge of likely etiologic agents [4]. Failure to identify and treat a relatively susceptible organism may result in the development of multidrug resistant strain of gram negative bacteria [5]. Infections of foot ulcers by Extended Spectrum BetaLactamase (ESBL) producing multidrug resistant gram

Manuscript received: $12^{\text {th }}$ Dec 2014

Reviewed: $16^{\text {th }}$ Dec 2014

Author Corrected: $4^{\text {th }}$ Jan 2015

Accepted for Publication: $16^{\text {th }}$ Jan 2015 negative bacteria in diabetic patients have been described frequently [6]. Several studies found methicillin-resistant Staphylococcus aureus (MRSA) in as many as $15-30 \%$ of diabetic wounds [7, 8]. Infections with multi drug resistant organisms (MDROs) may increase the duration of hospital stay and cost of management and may cause additional morbidity and mortality [5].

The aim of this study was to determine the hierarchy of the organisms most commonly isolated from patients with diabetic foot ulcers and antibiotic susceptibility pattern of these organisms at the onset and therefore empirical selection of right kind of anti-microbial therapy help in a better outcome in patients.

To assess the potential risk factors for infection of diabetic foot ulcers with multidrug resistant organisms and the outcome of these infections were also studied.

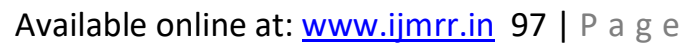




\section{Material and Methods}

The present study was undertaken during the period from September 2010 to June 2012 in our Microbiology Department. 78 diabetic patients with foot ulcer admitted at surgical wards of Krishna Hospital, Karad were included in the study.

\section{Inclusion criteria:}

- Type I and II diabetes of all the age groups and both sexes.

- Diabetic patients with foot ulcers of Grade I or more.

\section{Exclusion criteria:}

- Non-diabetic patients with foot ulcers.

- Diabetic patients with foot ulcers of Grade 0.

A semi structured questionnaire was developed to record the medical history, examination details and investigation reports. Diabetic foot ulcers were categorized into six grades based on Wagner classification [9].

\section{Microbiological Method:}

Culture specimens were obtained at the time of admission with proper history of antibiotic treatment either curettage of the base of ulcer, needle aspiration of abscess material or deep wound swab using aseptic technique. The specimen was kept in sterile culture tube and immediately transported to microbiology laboratory for processing of aerobic and anaerobic bacteria [10, $11,12]$.

\section{Antimicrobial Susceptibility Testing:}

Antimicrobial susceptibility testing of aerobic isolates was performed by the Kirby-Bauer disc diffusion method as recommended by Clinical and Laboratory Standard Institute (CLSI 2011 Volume 31 No. 1) [13].

\section{Multi drug resistant gram negative bacilli:}

The isolates which were resistant to beta lactam antibiotics containing oximino- group such as oximinocephalosporins such as Ceftazidime, Cefriaxone, Cephotaxime and Cefodoxime as well as oximinomonobactum such as Aztreonam, were taken as Multi drug resistant gram Negative organisms (MDROs) [14].

Gram-negative bacilli were subjected to first screening tests for the detection of ESBL. Confirmation of ESBL production was tested by Phenotypic Methods i.e. Double disc synergy test [14] and combined disc diffusion test [13]. Also Escherichia coli and Klebsiella bacilli were screened for detection of AmpC beta lactmase production. Confirmation of AmpC production was done by using AmpC disc test [15]. Screening and confirmation of Pseudomonas aeruginosa and Acinetobacter species for the detection of MBL was done by Imipenem - EDTA Combined Disc test [16]. Further confirmation of metallo-beta lactamase was done by the Imipenem-EDTA double disc synergy test. [17]. Staphylococcus species were tested for Methicillin resistance using $30 \mu \mathrm{g}$ Cefoxitin discs by Kirby Bauer Disc Diffusion method [13]. Quality control was performed using control strains Klebsiella pneumoniae ATCC 700603 and Escherichia coli ATCC 25922 for ESBL detection. Pseudomonas aeruginosa ATCC 27853 and ATCC Staphylococcus aureus 43300 were used for the detection of MBL and MRSA respectively according to National Committee for Clinical Laboratory Standards guidelines (CLSI 2011 Volume 31 No. 1) [13].

\section{Statistical methods:}

Statistical analysis was carried out after the raw data entered into MS Excel and analyzed into frequency percentage distribution. Chi-square test and unpaired $t$ test were applied for showing association between study variables. Two tailed $\mathrm{p}$ value of $<0.05$ was taken as significant.

\section{Results}

Mean age of the patients was $59.5 \pm 14.6$ years. Maximum, $70.51 \%$ cases were above the age of 50 years and as age increases, the chance of getting of Diabetic foot ulcer also increases $\left(\chi^{2}=43.42, p=0.0001^{*}\right)$. The proportion of male cases were higher,76.9\% as compared to females, $23.1 \%$ and difference was statistically significant $\left(\chi^{2}=9.07, \mathrm{p}=0.002 *\right)$. Majority of the patients were Type II Diabetes Mellitus i.e. 97.4\%. Mean duration of ulcer was $18.9 \pm 25.1$ days and ranged from 3 days to 180 days. Most common associated complication was neuropathy seen in 44 (56.4\%) cases. Majority of the ulcers belong to Grade III and IV i.e. $42(53.8 \%)$ and shows right leg ulcer predominance in $53(67.9 \%)$ cases.

In our study, a total of 78 specimens were cultured and $97.4 \%$ ulcer showed growth of organisms (76/78). A total of 139 isolates were obtained with 2 specimens being sterile .An average of 1.8 organisms per lesion was isolated. $34(44.7 \%)$ cases had growth of single organism while the rest were polymicrobial with $19.7 \%$ yielding 3 or more organisms.134 (96.4\%) isolates were aerobes whereas $5(3.6 \%)$ of the isolates were anaerobes. [Table 1] 
Table No. 1: Bacterial Isolates with Percentage

\begin{tabular}{|l|l|}
\hline Bacterial isolates & Percentage \\
\hline Total number of isolates & 139 \\
\hline Aerobes & $134(96.4 \%)$ \\
\hline Gram positive organisms & $41(30.6 \%)$ \\
\hline 1) Methicillin sensitive Staphylococcus aureus & $16(42.1 \%)$ \\
\hline 2) Methicillin resistant Staphylococcus aureus & $22(57.9 \%)$ \\
\hline 3) Streptococcus pyogenes & $3(2.2 \%)$ \\
\hline Gram negative organisms & $93(69.4 \%)$ \\
\hline 1) Pseudomonas aeruginosa & $32(23.9 \%)$ \\
\hline 2) Klebsiella species & $28(20.9 \%)$ \\
\hline 3) Escherichia coli & $19(14.2 \%)$ \\
\hline 4$) \quad$ Acinetobacter species & $7(5.2 \%)$ \\
\hline 5) Proteus species & $5(3.7 \%)$ \\
\hline 6$) \quad$ Citrobacter species & $2(1.5 \%)$ \\
\hline Anaerobes & $5(3.6 \%)$ \\
\hline
\end{tabular}

Table no.1 shows that in our study, a total of 78 specimens were cultured and $97.4 \%$ ulcer showed growth of organisms (76/78). A total of 139 isolates were obtained with 2 specimens being sterile. Also it shows the frequency of isolation of different organisms from diabetic foot ulcers. Gram negative organisms were most frequently isolated 93 (69.4\%) followed by gram positive. A total 41 (30.6\%) aerobic gram positive bacteria were isolated. Staphylococcus aureus was the most common gram positive organism $(28.4 \%)$.

The ratio of gram positive to gram negative was 1.2:2. Only Gram positive organisms, were found in 35 (46\%) cases and $14(18.4 \%)$ had only gram negative organisms. The remaining cultures had growth of both gram positive and negative organisms. Staphylococcus aureus was the most common gram positive organism (28.4\%). High levels of resistance were noted to: Penicillin, Ampicillin, Erythromycin, Cotrimoxazole, Ciprofloxacin. Maximum sensitivity was seen to Netilmicin, Linezolid. Table No. 2

Table No 2: Antimicrobial Susceptibility Pattern of Staphylococcus Aureus

\begin{tabular}{|l|l|}
\hline Drug & Staphylococcus aureus (38) \\
\hline Penicillin & $3(7.8 \%)$ \\
\hline Cotrimoxazole & $4(10.5 \%)$ \\
\hline Ampicillin & $3(7.8 \%)$ \\
\hline Ciprofloxacin & $3(7.8 \%)$ \\
\hline Ofloxacin & $10(26.3 \%)$ \\
\hline Norfloxacin & $8(21.6 \%)$ \\
\hline Levofloxacin & $15(39.4 \%)$ \\
\hline Azithromycin & $5(13.2 \%)$ \\
\hline Erythromycin & $4(10.5 \%)$ \\
\hline Amoxycillin+Clavulanic acid & $6(15.9 \%)$ \\
\hline Imipenem & $28(73.7 \%)$ \\
\hline Tobramycin & $18(47.4 \%)$ \\
\hline Cefoxitin & $16(42.1 \%)$ \\
\hline Linezolid & $24(63.2 \%)$ \\
\hline Teicoplanin & $18(48.6 \%)$ \\
\hline Netilmicin & $28(75.7 \%)$ \\
\hline Methicillin sensitive & $16(42.1 \%)$ \\
\hline Methicillin resistant & $22(57.9 \%)$ \\
\hline & \\
\hline
\end{tabular}


Research Article

Table no.2 shows in Staphylococcus aureus isolates high levels of resistance was noted to: Penicillin, Ampicillin, Erythromycin, Cotrimoxazole, Ciprofloxacin. Maximum sensitivity was seen to Netilmicin, Linezolid.

Fig No: 1 Distribution of Aerobic Gram Negative Bacteria

Fig No: 2 MRSA detection in Staphylococcus Aureus
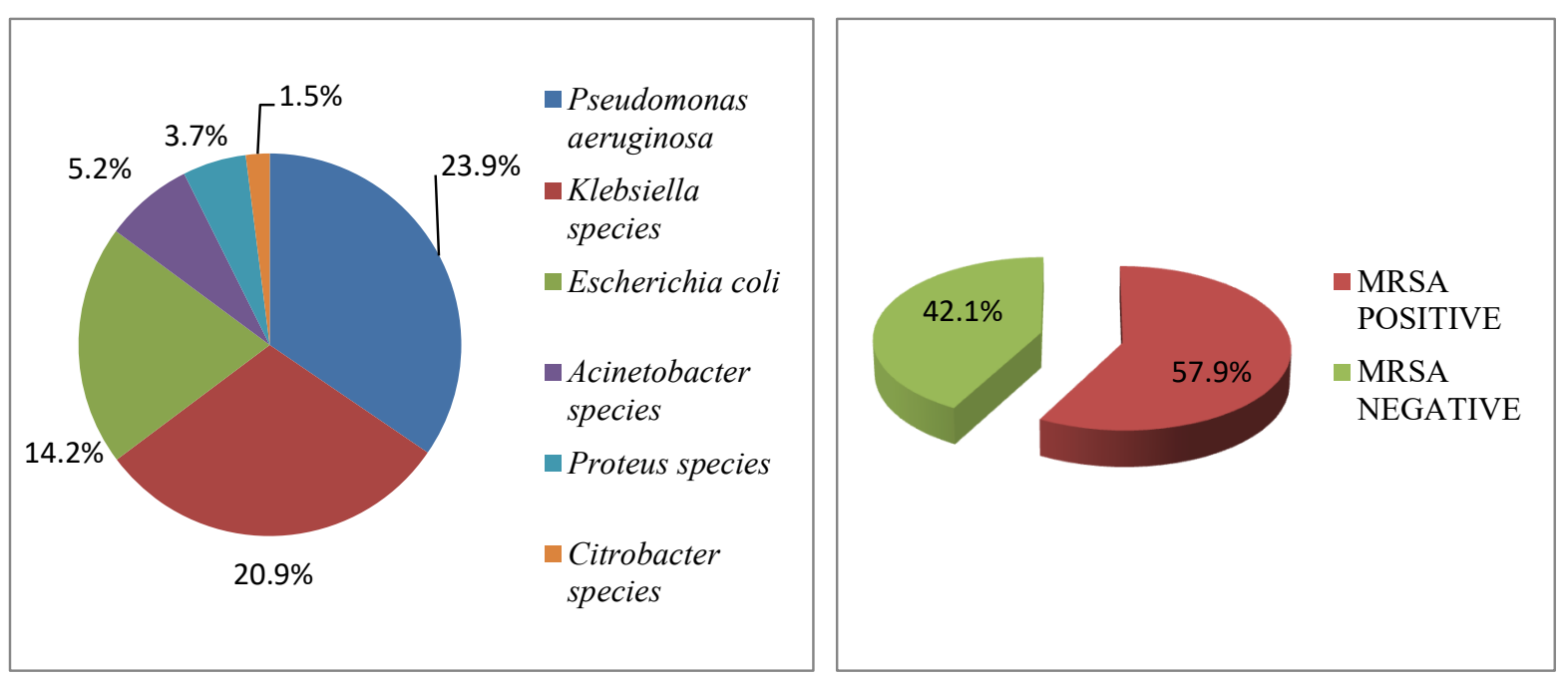

Most of the gram negative bacteria were resistant to various classes of antibiotics. Imipenem was the most effective antimicrobial agent against all the isolated gram negative bacterial species. Table No. 3

MRSA were seen in 22(57.9\%) isolates of Staphylococcus aureus. Figure No.2. Among gram negative organisms, 46(49.5\%) isolates showed ESBL production. Figure No.3. Of the total 19 isolates of Escherichia coli, 13(68.3\%) were ESBL positive, 4(21.5\%) were AmpC positive and 4(21.5\%) were both ESBL and AmpC positive. Similarly of the 28 isolates of Klebsiella species, 12(42.9\%) were ESBL positive, 3(10.7\%) were positive for AmpC and 3(10.7\%) were both ESBL and AmpC positive.

Of the total 32 isolates of Pseudomonas aeruginosa, 13(40.6\%) were only ESBL positive, 7(21.9\%) were MBL positive and $7(21.9 \%)$ were both ESBL and MBL positive. Similarly of the 7 isolates of Acinetobacter species only 5(71.4\%) were positive for MBL. ESBL were not detected in Acinetobacter species isolated.

Table No 3: Antimicrobial Susceptibility Pattern of Gram Negative Organisms

\begin{tabular}{|l|l|l|l|l|l|l|}
\hline Rug & $\begin{array}{l}\text { Pseudomonas } \\
\text { aeruginosa }\end{array}$ & $\begin{array}{l}\text { Escherichia } \\
\text { coli }\end{array}$ & $\begin{array}{l}\text { Klebsiella } \\
\text { species }\end{array}$ & $\begin{array}{l}\text { Acinetobacter } \\
\text { species }\end{array}$ & $\begin{array}{l}\text { Proteus } \\
\text { species }\end{array}$ & $\begin{array}{l}\text { Citrobacter } \\
\text { Species }\end{array}$ \\
\hline Cefalorid & 0 & 0 & 0 & 0 & $2(40 \%)$ & 0 \\
\hline Cefodoxime & 0 & 0 & $1(3.6 \%)$ & 0 & $2(4 \% 0)$ & 0 \\
\hline Cefoxitin & 0 & $10(31.3 \%)$ & $7(25 \%)$ & $1(14.3 \%)$ & $2(40 \%)$ & 0 \\
\hline Ofloxacin & 0 & $2(10.5 \%)$ & 0 & 0 & $1(20 \%)$ & $1(50 \%)$ \\
\hline Ciprofloxacin & 0 & $1(5.3 \%)$ & $2(7.1 \%)$ & 0 & $1(20 \%)$ & $1(50 \%)$ \\
\hline Norfloxacin & $3(9.4 \%)$ & $2(5.3 \%)$ & $2(7.1 \%)$ & $1(14.3 \%)$ & $2(40 \%)$ & $1(50 \%)$ \\
\hline Levofloxacin & $7(21.9 \%)$ & $5(29.4 \%)$ & $8(28.6 \%)$ & $2(28.6 \%)$ & $2(40 \%)$ & $1(50 \%)$ \\
\hline Ticarcillin & $3(9.4 \%)$ & 0 & $1(3.6 \%)$ & 0 & $3(60 \%)$ & $1(50 \%)$ \\
\hline Imipenem & $16(50 \%)$ & $16(94.1 \%)$ & $24(85.7 \%)$ & $6(85.7 \%)$ & $5(100 \%)$ & $2(100 \%)$ \\
\hline Meropenem & $17(51.1 \%)$ & $15(88.2 \%)$ & $12(42.8 \%)$ & $3(42.9 \%)$ & $4(80 \%)$ & $2(100 \%)$ \\
\hline Cefotaxime & $11(34.3 \%)$ & 0 & $1(3.6)$ & $1(14.3)$ & $4(80 \%)$ & 0 \\
\hline $\begin{array}{l}\text { Piperacillin }+ \\
\text { Tazobactam }\end{array}$ & $22(68.7 \%)$ & $10(58.8 \%)$ & $3(10.7 \%)$ & $3(42.9 \%)$ & $5(100 \%)$ & $1(50 \%)$ \\
\hline
\end{tabular}


Research Article

\begin{tabular}{|l|l|l|l|l|l|l|}
\hline Amikacin & $7(21.9 \%)$ & $5(29.4 \%)$ & $19(67.9 \%)$ & $1(14.3 \%)$ & $4(80 \%)$ & 0 \\
\hline Ceftazidime & $14(43.7 \%)$ & 0 & $2(7.1 \%)$ & $2(28.5 \%)$ & $4(80 \%)$ & 0 \\
\hline $\begin{array}{l}\text { Amoxycillin+ } \\
\text { Clavulanic acid }\end{array}$ & $8(25 \%)$ & $5(29.4 \%)$ & 0 & $1(14.3 \%)$ & $2(40 \%)$ & 0 \\
\hline Gentamicin & $6(18.7 \%)$ & $5(29.4 \%)$ & $9(32.1 \%)$ & $1(14.3 \%)$ & $3(60 \%)$ & $1(50 \%)$ \\
\hline Ceftriaxone & $9(28.1 \%)$ & 0 & $2(7.1 \%)$ & $1(14.3 \%)$ & $2(40 \%)$ & 0 \\
\hline Aztreonam & $9(28.1 \%)$ & 0 & $1(3.6 \%)$ & $2(28.5 \%)$ & $1(20 \%)$ & 0 \\
\hline Tobramycin & $20(62.5 \%)$ & $8(47 \%)$ & $21(75 \%)$ & $5(71.4 \%)$ & $2(40 \%)$ & $1(50 \%)$ \\
\hline
\end{tabular}

Table no. 3 shows most of the gram negative bacteria were resistant to various classes of antibiotics. Imipenem was the most effective antimicrobial agent against all the isolated gram negative bacterial species.

The association of study factors with MDROs is presented in Table No 4. There were no significant differences in the demographic characteristics between the two groups. Duration of diabetes shows borderline significant association with MDRO infection. As the duration of diabetes increases, the increase in the incidence of infection with MDRO is high ( $p$ value $0.0527 ; \mathrm{t}$ value 1.968$)$. Increase in the grade of ulcer did not show any association with MDROs ( $\mathrm{p}$ value 0.315 ).

Table No 4: Association of Study Characteristics - MDRO and Non MDRO

\begin{tabular}{|l|l|l|l|}
\hline & MDRO & Non MDRO & Value \\
\hline $\mathrm{n}$ & 50 & 28 & \\
\hline Age (yrs) & $58.66+14.69$ & $60.96+14.45$ & P 0.506 \\
\hline Male & $37(74 \%)$ & $22(78.6 \%)$ & P 0.860 \\
\hline Female & $13(26 \%)$ & $6(21.4 \%)$ & \\
\hline Duration of diabetes (yrs) & $7.2+8.75$ & $3.6+3.83$ & P 0.0527 \\
\hline Duration of ulcer (days) & $20.5+19.59$ & $15.9+33.00$ & P 0.448 \\
\hline Grade of ulcer & & & \\
\hline I & $4(8 \%)$ & $3(10.7 \%)$ & P 0.315 \\
\hline II & $11(22 \%)$ & $8(28.6 \%)$ & \\
\hline III & $11(22 \%)$ & $7(25 \%)$ & \\
\hline IV & $13(26 \%)$ & $9(32.1 \%)$ & \\
\hline V & $11(22 \%)$ & $1(3.6 \%)$ & \\
\hline Uncontrolled blood sugar & $40(80 \%)$ & $22(78 \%)$ & P 0.880 \\
\hline Controlled blood sugar & $10(20 \%)$ & $6(21.4 \%)$ & \\
\hline Smokers & $16(32 \%)$ & $11(39.3 \%)$ & \\
\hline Non-smokers & $34(68 \%)$ & $17(60.7 \%)$ & P 0.0539 \\
\hline Associated Complications & & & \\
\hline Neuropathy & $32(\%)$ & $12(60 \%)$ & P 0.399 \\
\hline Duration of hospital stay (days) & $25.4+17.36$ & $17+14.89$ & P 0.0345 \\
\hline Medical Treatment & $13(26 \%)$ & $16(57.2 \%)$ & P 0.0129 \\
\hline Surgical Treatment & $34(74 \%)$ & $12(42.8 \%)$ & \\
\hline Outcome & & $3(10.7)$ & \\
\hline Amputation & $16(32)$ & $25(89.3)$ & \\
\hline Non-amputation & $34(68)$ & & \\
\hline & & & \\
\hline
\end{tabular}


Research Article

The association of study factors with MDROs is presented in Table No. 4 . There were no significant differences in the demographic characteristics between the two groups. Duration of diabetes shows borderline significant association with MDRO infection. As the duration of diabetes increases, the increase in the incidence of infection with MDRO is high ( $p$ value 0.0527; $t$ value 1.968). Increase in the grade of ulcer did not show any association with MDROs ( P value 0.315). No significant associations of glycemic control with MDRO and non-MDRO infections are seen (P value 0.880 ).

Duration of hospital stay have been reported to increase with MDRO infections than Non-MDROs ( $\mathrm{p}$ value 0.0345 ; $\mathrm{t}$ value 2.153) increasing the cost of management. Significantly more patients with MDRO infections required surgical treatment ( $p$ value 0.0129). It was seen that the outcome of amputation was more when associated by infection with MDROS as compared to non-MDRO and was statistically significant ( $\mathrm{p}$ value 0.035 ).

Considering a fasting blood glucose level of $<110 \mathrm{mg} / \mathrm{dl}$ and postprandial level of $<160 \mathrm{mg} / \mathrm{dl}$ as glycemic control, the number of patients with glycemic control on day of admission was compared between those with and without MDRO infections.

No significant association of glycemic control with MDRO and non-MDRO infections had seen (p value 0.880).

\section{Discussion}

The mean age of the patients in our study was $59.5+14.6$ years. Most of our patients did not have access to diagnostic facilities as they were from rural areas. This is the reason for higher mean age of patients in our study.

Majority of the patient $39(50 \%)$ were in age group 50 to 70 years, which are comparable with study of Ekta Bansal et al [18] (51.3\%). Males were found to be more common victims and the ratio of male to female was 3.3:1. Male preponderance have observed in similar studies [18,19,5].

In the present study mean duration of diabetes was 6.5 years which is in close comparison to the study of Mamatha Samaga et al [20].

Majority of the ulcers belonged to Grade III and IV. 12 patients had extensive gangrene Grade V. Two cases with cellulites till thigh had to undergo above knee amputation.

As the grading of ulcer increased, the number of bacteria isolated also increased. Our study results are in comparison to study by Samir Paul et al [19] who has shown maximum number of cases 27 (36\%) with Grade III ulcers having maximum isolation of organisms.

In the present study peripheral neuropathy was seen in $44(56.4 \%)$ of cases. The feet were the target of peripheral neuropathy leading chiefly to sensory deficit and autonomic dysfunction.

In the present study $16(20.5 \%)$ patients had blood sugar level within controlled limits with isolated of one organism per case. And 62 (79.5\%) patient had poor glycemic control at the time of admission with an average of 1.6 organisms per case was isolated. High blood sugar level and increased number of isolation of organisms per case was seen in the study by Mamatha Samaga et al [20] which correlates with present study.

A total of 139 organisms were isolated from positive cultures of which, 134 (96.4\%) were aerobes and only $5(3.6 \%)$ isolates were anaerobes. This result correlates with the study of Mamatha Samaga et al [20] and EM Shankar et al [8] which shows the predominance of aerobic infections than anaerobic infection.

In present study polymicrobial infection was noted in $(55.3 \%)$ cases these findings correlates with similar study by Gadepalli et al [21], Samir Paul et al [19], Banashankari et al [5] and are in contrast to findings of Dhanasekaran et al [22] who documented $84 \%$ of monomicrobial infection.

In present study an average of 1.8 organisms per case was isolated. Study by Ekta Bansal et al [18] showed 1.5 isolates per case while, Gadepalli et al [21] showed 2.3 organisms per sample.

The ratio of gram positive to gram negative was 1.2:2. Our study results are in comparison with most of the authors. [21,5,8,22].

In our study the predominant gram positive cocci isolated was Staphyloccocus aureus 38 (28.4\%) followed by Pseudomonas aeruginosa, this was in accordance to the studies conducted in Indian tertiary care hospital $[18,23]$. 
Research Article

The most common gram negative organism was Pseudomonas aeruginosa 32 (23.9\%). The same results are seen in study by Umashankari et al [14] (20.9\%), Ekta Bansal et al [18] (22\%) and Samir Paul et al [19] (26.7\%).

Most of the gram negative bacteria were resistant to various classes of antibiotics. In present study ESBL production were noted in $46(49.5 \%)$ gram negative bacteria.

As compared to study by Samir Paul et al [19] we have observed high prevalence of ESBL detection in Pseudomonas aeruginosa $(62.5 \%)$. In present study of the total 19 isolates of Escherichia coli 4(21.5\%) were AmpC positive. Similarly of the 28 isolates of Klebsiella species 3(10.7\%) were positive for AmpC.

Our study showed 14(43.8\%) MBL production by Pseudomonas aeruginosa and 5(71.4\%) by Acinetobacter species which is in close concordance to the study by S. Murugan et al [17]. Of the total $38(28.4 \%)$ isolates of Staphylococcus aureus 22 $(57.9 \%)$ were MRSA positive. The result of the study of MRSA by Umashankari et al [14] in 53\%, Ekta Bansal et al [18] 55.5\% and Gadepalli et al [21] 56\% are comparable with the present study (57.9\%).

Maximum number of cases 4(57.2\%) infected with MRSA positive Staphylococcus aureus required surgical treatment i.e. debridement and amputation as compared to MRSA negatives 1 (14.3\%). Similarly 24(72.7\%) cases infected with ESBL producing bacteria required surgical treatment as compared to cases infected with non-ESBL producing bacteria $6(35.3 \%)$.

The findings are in correlation with study by Gadepalli et al [21] who showed significantly more patients with MDRO required surgical treatment.

The present study confirms that MDRO infection is extremely common in hospitalized patients with diabetic foot ulcer. This is in accordance with the report of Heurtier et al [24].

It was seen that the outcome of amputation was more when associated by infection with MDROs as compared to non-MDRO and was statistically significant. MDRO infection in foot ulcers was associated with the requirement for surgical treatment (P value 0.0129).

MDRO infections have been reported to increase hospital stay and cost of management [21], we found duration of hospital stay increased significantly in MDROs (p 0.0345).

Almost two-thirds of our patients were infected with MDROs and the prevalence of both MRSA isolates and ESBL-producing gram-negative bacteria was high. The only factors significantly associated with MDRO infection were the presence of neuropathy, duration of diabetes.

The high rates of antibiotic resistance observed in the present study may be due to the fact that ours is a tertiary care hospital with widespread usage of broad spectrum antibiotics leading to selective survival advantage of pathogens. The increasing prevalence of MDROs is disconcerting because infection with these organisms limits the choice of antibiotic treatment and may lead to a worse outcome.

\section{Conclusion}

In conclusion, the prevalence of MDROs was alarmingly high and was associated with increased requirement for surgical treatment. These findings suggest that prospective multicenter studies are required to assess the appropriate empirical antibiotic regimen in diabetic foot ulcers taking into consideration the etiology of ulcers. In addition, the results alert, us that proper management of antibiotics must be implemented to decrease the incidence of MDRO infection in this population, lest we soon run out of effective antimicrobials for our patients.

\section{Acknowledgements}

The author acknowledges to Principal K.I.M.S. for the permission and constant support during the study. We are indeed thankful to Medical director, K.H. for his kind co-operation with me in sample collection and $\mathrm{Mr}$. Kakade Sir ,Dept. of Community Medicine K.I.M.S Karad for helping me in the statistical work.

Funding: NIL

Permission from IRB: Yes

Conflicts of interest: The authors report no conflicts of interest

\section{References}

1. Anandi C, Alaguraja D, Natarajan V, Ramanathan M, Subramanian CS, Thulasiram M, Sumithra S. " Bacteriology of diabetic foot lesions". Indian J Med Microbiol 2004; 22(3): $175-8$ 
Research Article

2. Shankhdhar KLK, Shankhdhar U, Shankhdhar S. Diabetic foot problem in India:An overview and potential simple approaches in a developing country. Current Diabetes Reports 2008;8 (6): 452-7.

3. Shobhana R, Rao PR, Lavanya A, Ramachandran A. Cost burden to diabetic patients with foot complications: a study from Southern India. JAssoc Physicians India 2000;48 (12):1147-50.

4. Lipsky BA. "Medical treatment of diabetic foot infections." Clinical Infectious disease,2004 Aug 1; 39: Suppl 2: S 104-14.

5. G.S. Banashankari, H.K. Rudresh, A.H. Harsha. Prevalence of Gran negative bacteria in diabetic foot- A clinic microbiological study. 2012; 5(3):224-32.

6. Shazi Shakil, Asad U Khan. Infected foot ulcers in male and female diabetic patients: a clinicbioinformative study. Annals of Clinical Microbiology and Antimicrobials. 2010; 9:2. http:// www.ann- clinmicrob.com/content/9/1/2

7. Tentolouris N, Jude EB, Smirnof I, Knowles EA, Boulton AJ: Methicillin-resistant Staphylococcus aureus: an increasing problem in a diabetic foot clinic. Diabet Med 1999 Sept;16(9):767-71.

8. Shankar EM, Mohan V, Premlatha G, Srinivasn RS, Usha AR. Bacterial etiology of diabetic foot infections in South India. Eur J Intern Med. 2005;16 (8):567-70.

9. Dipali AC, Pal RB. "Study of fungal and bacterial infections of the diabetic foot." Indian J Pathol. Microbiol, 2002; 45(1): 15-22.

10. Sonnenwirth AC, Jarett L Eds. Gradwohl's Clinical Laboratory Methods and Diagnosis. $8^{\text {th }}$ Edition. St. Louis. The C.V. Mosby Company. 1980.

11. B S Nagoba. "Anaerobic Infections", Clinical Microbiology 2005, Chapter 19:165.

12. Vera L, Sutter, Diane M, Citron, Sydney M, Finegold. Anaerobic Bacteriology Manual. 3rd Edition. Los Angeles, California, 1980.

13. Wayne PA. National Committee for clinical laboratory standards. Performance standards for antimicrobial disc susceptibility testing; $21^{\text {st }}$ information supplement, Jan 2011; M100-S12.

14. Umasankari J, Jeya M, C. Sekar. Microbiological study of diabetic foot ulcers and analysis of ESBL activity of bacterial isolates. Journal of Pharmacy Research. 2012; 5(4):2329-32.

15. Paul R. Ingram. Comparison of methods for AmpC $\quad \beta$-lacatamase detection in Enterobacteriaceae, http:// jmm.sgmjournals. org/content/60/6/715.full

16. Mohammad Zubair, Abida Malik, Jumal Ahmad. Prevalence of metallo beta lactamase producing Pseudomonas aeruginosa isolated from diabetic foot ulcer patients. Diabetes and Metabolic Syndrome. Clinical Research and Review. 2011;5 (2):90-2.

17. S. Murugan, R. Bakkiya Laxshmi, P.Uma Devi, K.R.mani. Prevalence and antimicrobial susceptibility pattern of metallo $\beta$-lactamase producing Pseudomonas aeruginosa in diabetic foot infection. International Journal of Microbiological Research 2010; 1(3):123-8.

18. Ekta Bansal, Ashish Garg, Sanjeev Bhatia, Ak Attri, Jagdish Chandar. Spectrum of microbial flora in diabetic foot ulcers. 2008; 51(2):204-8.

19. Samir Paul, Lovely Barai, Ashraf Jahan, Ashraful Haq. A bacteriological study of diabetic foot infection in an Urban Tertiary Core Hospital of Dhaka City. Ibrahim Med. Coll. J. 2009; 3(2):504.

20. Mamtha Samaga. Bacteriologica (Aerobic and Anaerobic) profile of diabetic foot ulcer. Rajiv Gandhi University of Health Sciences, Bangalore. 2008.

21. Gadepalli R, Dhawan B, Sreenivas V, Kapil A, Ammini AC, Chaudhry R. A clinicmicrobiological Study of Diabetic Foot ulcers in an Indian Tertiary Care Hospital. Diabetes Care, 2006; 29(6):1727-31.

22. Dhansekaran G, Satry G. Viswanathan M. Microbial pattern of Soft tissue infections in diabetic patients in South India. Asian J. Diabet. $2003 ; 5: 8-10$. 
23. R. Sasikala, R.Latha,N. Muruganandam,K. Senthilkumar Surveillance on multidrug resistant organism (CMDRO) associated with diabetic foot ulcer in Pondicherry. Internet Jour. of Microbiology. 2008; 5(1)DOI:10:5580/9be
24. Hartemann Heurtier A, Robert J. Diabetic foot ulcer and multidrug resistant organisms; risk factors and impact. Diabet Med. 2004;21(7): 7105.

\section{How to cite this article?}

Chavan S K, Karande GS, Chavan K B. Bacterial Profile and pattern of antimicrobial drug resistance in Diabetic foot ulcers at Tertiary care hospital. Int J Med Res Rev 2015;3(1):97-105. doi: 10.17511/ijmrr.2015.i1.16 